\title{
Instrumentos clássicos da avaliação: a prova em destaque
}

\author{
Alesandra Ferreira Bento Souza* \\ Cláudia Rodrigues de Camargo Martins** \\ Silvia Ferreira de Macedo*** \\ Tatiane Cristini da Silva****
}

\begin{abstract}
Resumo
O objetivo deste artigo é socializar as experiências de formação e atuação docente, ocorridas durante o minicurso Instrumentos clássicos da avaliação: a prova em destaque realizado pelas integrantes do Grupo de Estudos e Pesquisas em Avaliação Educacional (GEPAE), vinculado à Faculdade de Educação da Universidade Federal de Uberlândia (UFU), ocorrido durante o III Seminário Municipal de Literatura e Língua Portuguesa e I Seminário Regional de Avaliação, em 2010. Utilizamos, como referencial teórico para as nossas discussões, as produçóes de alguns autores como Freitas (2002), Luckesi (1999), Vasconcellos (2000), Sordi (2001) e Romão (2001). Os debates acerca da elaboração e aplicação de provas vêm impulsionando reflexôes e pesquisas sobre suas consequências e o poder que exerce no ambiente escolar. A supervalorização na memorização de informaçóes revela poucos dados sobre a aprendizagem efetiva dos discentes, fortalecendo uma cultura do medo, da classificação e culpabilização pelos resultados não alcançados. Nossa crítica refere-se ao fato de sua utilização com um fim em si mesmo e não como um meio possível para repensar e replanejar determinadas práticas. Se a prova é necessária, precisamos, então, de princípios e critérios para fundamentá-la.
\end{abstract}

Palavras-chave: avaliação, instrumentos, prova.

\section{Classical assessment tools: exams steal the limelight}

\footnotetext{
Abstract

The aim of this study is to socialize the formation and teaching experiences, which took place during the short course Classical assessment tools: exams steal the limelight taken by the members of GEPAE - the Educational Assessment Study and Research Group in the Education Faculty at the Universidade Federal de Uberlândia (UFU) during the 3rd

* Integrante do Grupo de Estudos e Pesquisas em Avaliação Educacional (GEPAE) da UFU e profa. da Rede Municipal de Uberlândia. E-mail: alesouza.ufu@gmail.com

** Integrante do GEPAE da UFU PPGED e vice-diretora de escola da Rede Municipal de Uberlândia. E-mail: camargoemartins@uol.com.br

*** Integrante do GEPAE da UFU profa. da Rede Municipal de Uberlândia. E-mail:silvia@uberlandia. com

**** Integrante do GEPAE e profa. da Educação Básica de Uberlândia. E-mail: tatianecristini@hotmail. com
} 
Municipal Seminar on Literature and Portuguese language and the 1st Regional Assessment Seminar. As a theoretical framework for the discussion, authors such as Freitas (2002), Luckesi (1999), Vasconcellos (2000), Sordi (2001) and Romão (2001) were used. Debate on the designing and application of exams has brought about reflection and research on the consequences and power they exert in the school environment. Overvaluation of memorization reveals very little about the effective learning of students. Rather it reinforces a culture of fear, classification and guilt about unachieved results. We criticize the fact that it is used as an end in itself and not as a possible means towards rethinking and re-planning certain practices. If exams are needed, then their underlying principles and criteria need to be defined.

Keywords: assessment, tools, exams.

Historicamente, a temática avaliação da aprendizagem reduziu-se, no ambiente escolar, à mera utilização de instrumentos para a verificação, classificação e segregação de alunos. A prova, como o instrumento mais utilizado, sempre ocupou destaque no processo de ensino e aprendizagem, colocando-se como fonte única e eficaz na consolidaçáo dos resultados obtidos pelos discentes. Essa prática gerou e ainda gera uma cultura de exclusão no seio escolar, uma vez que o produto publicado estigmatiza parte do alunado como incompetente e fracassado. Mas, afinal, por que a prova possui esse caráter seletivo?

Alguns teóricos renomados, como Freitas (2002), Luckesi (1999), Vasconcellos (2000), Sordi (2001) e Romão (2001) têm se debruçado há décadas para desvelar essa cruel realidade do poder que a prova exerce sobre os discentes. Segundo Luckesi (1999), o que comumente se denomina avaliação, na verdade, nada mais é que o simples ato de verificar o que o aluno aprendeu, sem possíveis retomadas do conteúdo que não foi apreendido. Os problemas que se apresentam na utilização das provas referem-se à elaboração de instrumentos arbitrários, que pouco informam sobre a real incorporação do conteúdo estudado e transformado em conhecimento, traduzindo-as em elementos isolados do processo de ensino e aprendizagem, nas quais mensuram-se os resultados para aprovar ou reprovar os alunos.

A pedagogia do exame, pautada na memorização e na utilização de provas para a obtenção de informaçóes sobre o que os alunos sabem ou não, tem contribuído significativamente para a perpetuação de uma cultura que culpabiliza o indivíduo pelo seu fracasso escolar, tornando-o o único responsável por náo conseguir atingir os objetivos previstos pelo professor.

Essa organização da avaliação não se apresenta neutralizada, ao contrário, ela se faz dotada de intençốes que atendem ao regime vigente, 
posto que, na sociedade capitalista, a segregação é parte de um conjunto de aspectos políticos, sociais, econômicos e culturais que promovem o funcionamento da engrenagem social. Nesse contexto, os processos avaliativos cumprem uma função que é a de habilitar os aptos e inaptos a ocuparem um espaço no corpo dessa sociedade e, dessa forma, manter a configuração social meritocrática.

A utilização de testes, provas e exames entendidos como avaliação é reflexo dos interesses do modelo de sociedade em que vivemos, cujo desempenho individual se baseia no merecimento, ou seja, o homem é visto como um ser competitivo que precisa demonstrar a capacidade individual de superar os obstáculos apresentados e avançar no meio social.

Nos espaços escolares, os efeitos desses preceitos são facilmente percebidos quando observamos algumas práticas avaliativas, que se desenvolvem com um fim em si mesmas e não como parte de um processo de aprendizagem. Elas apresentam-se reduzidas à elaboração de instrumentos, especialmente de provas, para verificar se determinado conteúdo foi apreendido. Os alunos que não conseguem obter resultados satisfatórios, do ponto de vista da escola, são marginalizados e excluídos, uma vez que recai sobre eles a culpa por não terem conseguido alcançar aquilo que foi projetado. Considerando que os esforços individuais foram insuficientes para ultrapassar a etapa preestabelecida, a escola não pratica a retomada de matérias já estudadas, deixando à deriva os alunos cujas notas se apresentaram deficitárias. Dessa forma, vemos como a segregação acontece no interior das instituiçóes educacionais.

Como forma de ruptura dessa lógica excludente, temos contribuiçóes teóricas que sinalizam para a superação das práticas avaliativas classificatórias. Sordi (2005) e Fernandes (2009) nos apresentam a possibilidade de avaliarmos para a aprendizagem e não simplesmente para a verificação. Essa "outra face da avaliaçáo" coloca o professor como agente interlocutor de um processo de ensino com o propósito de organizar situaçóes didáticas para que os alunos possam aprender os conteúdos estudados. Nessa vertente, o erro náo é considerado como punição, mas sim como uma forma de identificação de algo que não foi aprendido e que precisa ser retomado.

Ressaltamos que não defendemos a abolição do instrumento prova, ao contrário, validamos sua necessidade e utilidade como um momento privilegiado do estudo. Se ela cumprir a função de apontar o que o aluno compreendeu ou não, se for útil à própria avaliação da proposta de trabalho 
do professor, entáo a prova cumpre sua função e atinge seu objetivo. Nessas condiçóes, não concebemos a utilização da prova como mero instrumento de verificação, classificação e quase sempre de punição. Nossa defesa é pela utilizaçáo da prova como instrumento que auxilia o processo de ensino e aprendizagem.

A prova não precisa causar sofrimento. Diga-se de passagem, este sentimento não é exclusivo do aluno, mas o é de igual modo ao professor que avalia. Se, para muitos professores, "as notas e as provas funcionam como redes de segurança em termos de controle exercido pelos professores sobre seus alunos [...]", segundo Hoffmann (1993, p. 24), também não se pode negar que, dependendo de seu resultado, este é assumido como forma de fracasso para ambos. $\mathrm{O}$ aluno que se esforça e não alcança o resultado desejado é tomado por inquietaçóes e frustraçóes, o professor pode considerar que todo o seu trabalho foi em vão e assim as duas faces do processo de ensino não se unem em busca do melhor, que é a aprendizagem.

O que pode ser feito diante de tão dramático cenário? Defendemos, como passo inicial, um processo de reflexão, entre os protagonistas das escolas, sobre as práticas avaliativas ensejadas e sobre o papel exercido pela prova no ambiente escolar. Entendemos que, para desconstruir uma concepçáo que causa angústia, sofrimento e insegurança em professores e alunos, faz-se necessário construir outra concepção de utilização para este instrumento e, a partir desta nova concepção, lançar novos olhares sobre o uso da prova como meio de se avaliar os alunos. Se a prova náo deve gerar essa coletânea de sentimentos, se ela não tem cumprido o seu papel, é preciso transformá-la para que seja de fato significativa tanto aos professores como aos alunos.

O modo de avaliar concebido por algumas escolas não deixa espaço para a reflexão sobre os anseios e as necessidades da sociedade em que estas escolas estão inseridas. $\mathrm{O}$ acúmulo de informaçóes memorizadas, distantes, por vezes, da vivência dos discentes, acaba por implicar um ensino irrelevante, uma aprendizagem sem significado e uma avaliação meramente verificativa. Nessa lógica, ainda que o aluno consiga gabaritar uma prova, transcrevendo todas as informaçóes que conseguiu memorizar, muitas vezes de forma idêntica ao que foi dito pelo professor, isso não significa que ele obteve êxito na aprendizagem.

A máxima e tâo desejada não é a nota, mas, antes, é a verificação de que o conhecimento estudado está sendo apreendido pelos alunos. Nesse 
sentido, os resultados não cumprem a função de punir e de reprovar, mas de auxiliar os professores e alunos na superação dos problemas identificados no percurso do ensino e da aprendizagem; isso significa utilizar a prova como instrumento que analisa se houve aprendizado significativo. Romáo (2001, p. 96) aborda um dos princípios fundamentais que sustentam nossa discussão, já que, para ele, "a avaliação da aprendizagem é um momento privilegiado de estudo e náo um acerto de contas".

Partindo dessa compressão, empreendemos esforços no minicurso Instrumentos clássicos da avaliação: a prova em destaque para refletirmos coletivamente os aspectos relevantes sobtre a utilização de provas como meio de verificação da aprendizagem.

Num primeiro momento, propomo-nos a conhecer as participantes do minicurso e as concepçóes de cada uma acerca da avaliação, a partir de suas vivências como alunas. Para tanto, aplicamos a dinâmica autodesenho, em que cada integrante explicitava as suas impressóes sobre a avaliação. Com lápis de cor, giz de cera, folhas e outros materiais, as participantes deveriam representar, da maneira como desejassem, suas experiências, como alunas, no processo avaliativo vivenciado ao longo de seus estudos.

Percebemos, sem muito espanto, que as experiências, em grande parte, não foram positivas do ponto de vista das aprendizagens. Segundo relatos das próprias participantes, a prova, na maioria das vezes, era um momento angustiante e gerador de sentimentos como o medo, a frustração ou o alívio quando a fase de provas se findava na escola. Como o grupo compartilhou os significados de suas representaçóes, este foi um momento em que as participantes puderam relembrar as suas experiências e começar a refletir sobre a sua atual prática avaliativa em sala de aula, visto que muitas delas já atuavam como profissionais da educação.

Após a etapa de discussão, apresentamos ao grupo algumas produçôes teóricas de autores que pesquisam e estudam a prática avaliativa que defendemos, que discorrem sobre dimensóes, conceitos, concepçóes e instrumentos de avaliação. Dessa forma, tivemos a oportunidade de mostrar que existem estudiosos preocupados com o reflexo que a avaliaçáo malsucedida pode causar nos estudantes e também como essa prática excludente afeta o desenvolvimento da aprendizagem.

Depois, de forma proposital, analisamos algumas provas com várias questóes mal elaboradas que, por não se apresentarem objetivas ou contextualizadas, favoreciam a dubiedade de interpretaçáo. Nesse caso, 
as integrantes do curso perceberam como uma questáo mal elaborada em uma prova pode gerar diferentes repostas e diversos questionamentos. A partir dessas reflexôes, ressaltamos a necessidade de elaborarmos provas com questóes que não permitam mais de uma resposta, a não ser em casos específicos em que o educador deseja obter diferentes respostas.

Romão (2001) constata que essa é uma característica muito frequente encontrada em provas e que isso deixa o aluno "nas mãos do professor", pois na falta de um parâmetro de correção, quem elaborou a prova considerará a resposta como correta ou incorreta de acordo com o seu entendimento ou a sua expectativa do que o aluno deveria ter respondido. Para melhor compreensão dessa discussáo, apresentamos vários exemplos de questóes que foram elaboradas sem contextualização e que não traziam explícitos os critérios de correção.

As questóes utilizavam palavras de comando sem precisão de sentido no contexto como "comente", "dê sua opiniáo", "o que você sabe sobre". Romão (2001, p. 104) alerta para o fato de que estas expressóes devem ser evitadas, mas se forem utilizadas "precisam ter sentido no contexto em que são usadas permitindo a parametrização correta das questóes”, já que o sucesso da resposta dependerá em muito da estrutura clara e precisa da pergunta.

Para agregar mais elementos à discussão a que nos propusemos realizar, fizemos uso de textos motivadores e geradores de reflexôes, para que as participantes se sensibilizassem sobre a importância de se analisar cuidadosamente os aspectos que podem influenciar os resultados das provas. Dessa forma, finalizamos o primeiro dia do minicurso com reflexôes para fomentar, nas participantes, o desejo de entender melhor a importância da elaboração de uma prova. No segundo dia, fizemos a discussão sobre os princípios gerais de elaboração de questôes, as finalidades e os critérios de avaliação de provas embasadas em pressupostos teóricos. Nesse dia, cada participante recebeu um mesmo texto fotocopiado contendo uma questão dissertativa para a devida correção e para mensurar quantitativamente a questáo entregue. Essa experiência evidenciou que uma mesma questáo pode apresentar correçóes e avaliaçóes distintas. Houve casos de discrepância relevante, cujas notas se opuseram de maneira extremada. As participantes socializaram com o grupo os critérios utilizados para a correção do texto, refletindo coletivamente a arbitrariedade cometida pelos professores no tocante ao processo de elaboraçáo, aplicação e correçấo de provas. 
Como forma de contribuição para o aprofundamento das nossas reflexóes, uma professora dos anos iniciais da rede municipal de ensino apresentou para as participantes uma possibilidade de elaborar e aplicar provas interdisciplinares, contemplando questóes que não se limitavam à simples memorização de conteúdos, ao contrário, as questôes exigiam análises e interpretaçóes e apresentavam elementos para a verificação da aprendizagem de todo o processo de ensino.

Essa troca de experiências contribuiu, segundo relatos das participantes, para aprofundarmos os debates acerca dessa temática e para refletirmos sobre o que tem sido feito em sala de aula, evidenciando as fragilidades e os desafios da avaliação da aprendizagem. Conforme o depoimento a seguir, uma das cursistas descreveu o significado da prova no transcorrer do seu processo educativo:

Para mim, a prova sempre significou a "hora da verdade", mesmo que esta verdade fosse dolorosa. Agora compreendo melhor sua função. (Aluna A, do curso de Pedagogia da UFU, participante do minicurso)

Muito avançamos no campo teórico desde a década de 1980 a respeito das contribuiçóes da avaliação, mas ainda faltam publicaçóes de professores que convivem com o cotidiano da sala de aula, e que se propóem, na árdua luta do trabalho pedagógico, em romper com a dicotomia teoria e prática. Neste sentido, a contribuição de uma das ministrantes desse minicurso foi muito satisfatória. Sua prática pedagógica nos permitiu demonstrar que a avaliação, numa perspectiva de construção significativa do conhecimento, é possível. Percebemos tal contribuição no relato de uma estudante do Curso de Pedagogia da UFU, ao descrever sua satisfação em aprender que existem outras formas mais eficazes de avaliar os alunos:

A prova, bem como todos os processos avaliativos, se apresentou e ainda se apresenta como meio de ameaça, puniçáo, o que acaba por criar medo, ansiedade e traumas nos alunos quando ouvem a palavra prova. Disso sempre soube, mas o interesse que a oficina veio a oferecer é sobre as diferentes formas de avaliar, sem que esta seja motivo de apreensão dos estudantes. Pude notar a importância de não avaliar unicamente pela verificação, mas sim por meio da reflexão [...] a experiência de uma professora que apresentou seu projeto para a turma foi linda! A maneira como abordou as várias disciplinas, bem como após o trabalho buscou avaliar também de maneira interdisciplinar [...]. (Aluna B, do curso de Pedagogia da UFU, participante do minicurso) 
Muitos professores e alunos concebem a prova como o instrumento de avaliação mais eficaz do processo de ensino e aprendizagem. O docente a entende como forma de verificar se o aluno aprendeu e o discente vê a oportunidade de deixar para estudar ou decorar os conteúdos no último momento antes de sua realização. No caso do minicurso, as participantes relembraram suas afliçóes com os professores que as avaliavam apenas com provas e puderam refletir sobre sua própria prática no interior das salas de aula, agora como professoras. $\mathrm{O}$ uso de um único instrumento para avaliar todo um processo é, de fato, insuficiente para fornecer as informaçóes de que o professor precisa para ajudar seu aluno a superar as dificuldades durante o processo de ensino e de aprendizagem (MENDES, 2006). O relato abaixo demonstra os sentimentos de uma aluna durante as avaliaçóes:

Eu nunca gostei de provas, me deixavam aflita, apreensiva, tinha muito medo de que quando chegar a hora me desse um branco, como acontecia com muitas amigas. Gostava mais das professoras que utilizavam outras formas de avaliar como seminários, teatros e até a construção de paródias [...]. (Aluna C, do curso de Pedagogia da UFU, participante do minicurso)

Por fim, explicitamos nossa crítica contrapondo o fato de a prova, um instrumento táo valioso, ser utilizada com um fim em si mesma e não como um meio possível de repensar e replanejar a prática educativa. Se a prova ainda é necessária, que saibamos utilizá-la como instrumento privilegiado da avaliação. Precisamos, então, de princípios e critérios para fundamentála. Precisamos que ela tenha seu papel e seus objetivos claramente explicitados aos interessados e que passe a ser utilizada de forma que os resultados obtidos sirvam ao efetivo aprendizado dos estudantes, como à retomada dos conteúdos que não foram aprendidos e ao replanejamento docente se verificado que o processo de ensino apresentou-se inadequado ou insuficiente, sem, contudo, ser a única maneira de se verificar a aprendizagem dos alunos.

Por esse motivo, em lugar de apregoarmos os malefícios da prova e levantarmos a bandeira de uma avaliação sem prova, procuramos seguir o princípio: se tivermos que elaborar provas, que sejam bem feitas, atingindo seu real objetivo, que é verificar se houve aprendizagem significativa de conteúdos relevantes. (MORETTO, 2001, p. 96)

A raiz do problema não se resume ao uso ou não uso deste instrumento: 
[...] vai além do uso ou não da prova, vai além de sua capacidade ou não de verificar o conteúdo aprendido. Portanto, não basta abolir ou aderir a esse instrumento, é preciso entender que a avaliação precisa estar a serviço da aprendizagem. (MENDES, 2006)

Com alguns cuidados e com uma abordagem adequada, afirmamos, entáo, que é possível lançar mão deste e de outros instrumentos como momento privilegiado de práticas avaliativas em que o processo de aprendizagem esteja em destaque para toda a instituição educacional. Dessa forma, temos a convicção de que defendemos uma prática possível de acontecer, que vai ao encontro de um ideal de sociedade diferente do que vivenciamos, mas que, ao longo dos anos, tem conquistado espaço e mostrado possibilidades de mudanças positivas, a favor de uma avaliaçáo em que todos possam aprender, longe dos preconceitos e das práticas segregacionistas e excludentes.

\section{Referências}

FERNANDES, Domingos. Avaliar para aprender: fundamentos, práticas e políticas. São Paulo: Unesp, 2009.

FREITAS, Luiz Carlos de. Avaliação: construindo o campo e a crítica. Florianópolis: Insular, 2002.

HOFFMANN, Jussara. Avaliação mediadora: uma prática em construção da pré-escola à universidade. Porto Alegre: Mediação, 1993.

LUCKESI, Cipriano Carlos. Avaliação da aprendizagem escolar. São Paulo: Cortez, 1999.

MENDES, Olenir Maria. Formação de professores e avaliação educacional: o que aprendem os estudantes das licenciaturas durante sua formação. Tese (Doutorado em Educação) - Faculdade de Educação, FE/USP, São Paulo, 2006. 166 p.

MORETTO, Vasco Pedro. Prova: um momento privilegiado de estudo, não um acerto de contas. Rio de Janeiro: DP\&A, 2001.

ROMÃO, José Eustáquio. Avaliação dialógica: desafios e perspectivas. 3. ed. São Paulo: Cortez, 2001. (Guia da Escola Cidadã, v. 2). 
SORDI, Mara Regina Lemes de. Alternativas propositivas no campo da avaliação: por que não? In: CASTANHO, Sérgio; CASTANHO, Maria Eugênia (Org.). Temas e textos em metodologia do ensino superior. CampinasSP: Papirus, 2001. p. 171-182.

SORDI, Mara Regina L. de. Recuperação da nota, do conteúdo, do conhecimento, do aluno, do homem? Escolhas que fazem a diferença. EDUC@ação, Rev. Ped., Unipinhal, Espírito Santo do Pinhal, SP, v. 1, n. 3, jan./dez. 2005.

VASCONCELLOS, Celso dos Santos. Avaliação: concepção dialéticalibertadora do processo de avaliação escolar. São Paulo: Libertad, 2000.

Recebido em: 25 jun. 2012

Aceito em: 10 ago. 2012 